\title{
Graduate Student Literature Review: Heat abatement strategies used to reduce negative effects of heat stress in dairy cows*
}

\author{
C. A. Beckert (i) and A. E. Stoneł (1) \\ Department of Animal and Dairy Science, Mississippi State University, Starkville 39762
}

\begin{abstract}
The southeastern United States experiences an extended hot season with a high environmental temperature and relative humidity. With increasing global temperatures, managing dairy cattle in regions with tropical, subtropical, and Mediterranean climates is becoming an increasing challenge. Heat-stressed cows will decrease feed intake, decrease productivity, and increase respiration rate in an attempt to maintain internal body temperature. Temperature-humidity index (THI) is a unitless value that has been used to measure the magnitude of heat stress on dairy cows. Many researchers have studied the THI threshold at which dairy cattle begin to experience heat stress. When housing cows in a confinement setting, a pasture-based setting, or a combination of the two, the appropriate heat abatement should be implemented to allow cows to perform to their potential and to improve overall animal welfare. This review summarizes heat abatement strategies that have been studied to reduce the negative effects of heat stress.
\end{abstract}

Key words: heat stress, dairy cow, heat abatement

\section{INTRODUCTION}

Global climate change has already had observable effects on the environment, including glaciers melting, plant and animal ranges shifting, trees flowering sooner, accelerated sea level rise, and more intense heat waves. Environmental temperatures are predicted to increase by $1.5^{\circ} \mathrm{C}$ globally between 2032 and 2050 (IPCC, 2018). The southeastern United States experiences extended periods of hot weather with high relative humidity and

Received March 15, 2020

Accepted May 15, 2020.

* Submitted to the 2021 ADSA Foundation Graduate Student

Literature Review Competition (Production, MS) on June 3, 2020.

†Corresponding author: cab1286@msstate.edu

¥Advisor (Amanda.stone@msstate.edu) little relief from the heat in the evening hours (West, 2003). With nearly 4 to 6 mo of high ambient temperatures and humidity, dairy producers are faced with a continuously more challenging task when it comes to housing their animals.

When environmental temperatures exceed the internal body temperature of a cow, her natural heat dissipation methods become inadequate. In periods of heat stress, when a cow is unable to regulate her internal body temperature, her health, productivity, and behavior are dramatically altered (West, 2003; Tao et al., 2018). Some negative effects associated with heat stress include increased body temperature, increased respiration rate, decreased feed intake, decreased milk production, and decreased fertility; in extreme cases, heat stress can result in death (Brown-Brandl et al., 2005; Mader et al., 2006). These production losses and decreases in performance lead to huge economic losses for the dairy industry of more than $\$ 900$ million annually (St-Pierre et al., 2003). Monitoring environmental variables and altering the environment of dairy cattle as necessary can help improve overall cow comfort and animal welfare and reduce the annual economic loss due to heat stress.

Housing and management can play a role in the severity of heat stress experienced by dairy cattle. By altering housing and management strategies, negative heat stress responses can be reduced or mitigated (Polsky and von Keyserlingk, 2017). Various cooling options exist for dairy cattle but the success of each cooling option may differ depending on the climate of a specific region and the type of housing (e.g., confinement or pasture). This review is a summary of heat abatement strategies that have been studied to reduce the strain of heat stress on dairy cattle.

\section{ENVIRONMENTAL TEMPERATURE MONITORING}

\section{Temperature-Humidity Index}

To summate the intensity of heat stress exposure on dairy cows, various weather variables (ambient temperature, wind speed, relative humidity, solar ra- 
diation) can be measured. Two commonly measured environmental parameters to assess heat stress include ambient temperature and relative humidity (Nienaber et al., 1999). Ambient temperature consists of both dry and wet bulb temperature. Dry bulb temperature is the actual air temperature shielded from moisture and solar radiation. Wet bulb temperature is the measure of moisture or water vapor in the air. By including relative humidity $(\mathbf{R H})$ in an equation for measuring thermal stress, the amount of moisture the air can hold at a specific temperature before it is condensed to dew is accounted for. An increased RH increases the likelihood of cattle becoming heat stressed (Herbut and Angrecka, 2018).

Temperature-humidity index (THI) is a unitless value used to measure the severity of heat stress on dairy cows (Mader et al., 2006; Bohmanova et al., 2007). Temperature-humidity index was first introduced by Thom (1959) to assess the effect of heat stress on humans. It has since been adapted to describe thermal effects that influence heat stress in dairy cattle (De Rensis et al., 2015).

Bohmanova et al. (2007) reported that THI can be an indicator of milk yield in the southeastern United States. Temperature-humidity index equations that weight humidity more heavily are more accurate for cattle in humid regions, like Georgia, whereas THI equations that decrease the weighting of humidity in the equation are better for cattle in arid regions, like Arizona. An equation used to calculate THI for cattle in humid climates is

$$
\mathrm{THI}=\left(0.35 \times \mathrm{T}_{\mathrm{db}}+0.65 \times \mathrm{T}_{\mathrm{wb}}\right) \times 1.8+32,
$$

where $\mathrm{T}_{\mathrm{db}}=$ dry bulb temperature and $\mathrm{T}_{\mathrm{wb}}=$ wet bulb temperature in ${ }^{\circ} \mathrm{C}$ (Bianca, 1962).

Cow-specific data are not included in THI formulas. The THI is often used in lieu of body temperature of cattle experiencing heat stress (Buffington et al., 1981; Gaughan et al., 2008) to predict milk loss (Bohmanova et al., 2007), and it is negatively correlated with production performance and reduced overall performance (West, 2003). Researchers have consistently used a THI $\geq 72$ as the temperature threshold at which dairy cows begin to experience heat stress (Ravagnolo et al., 2000). Collier et al. (2005) reevaluated the impact of THI on high-producing dairy cows and reported that threshold to be an underestimation of when dairy cows begin experiencing heat stress. In an Arizona study, Collier et al. (2005) reported that milk yield of high-producing cows decreased by $2.2 \mathrm{~kg} / \mathrm{d}$ every $24 \mathrm{~h}$ at a daily mean THI of 68 . In addition, researchers have reported that the THI 24 to $48 \mathrm{~h}$ before a decrease in milk yield may be the best indicator for milk loss (West, 2003; Spiers et al., 2004). This could indicate that cooling methods should be implemented $48 \mathrm{~h}$ before an anticipated high THI to reduce the severity of the milk loss. Most weather stations near farms provide THI data, making this measurement a useful tool for producers to make management decisions regarding heat stress (Polsky and von Keyserlingk, 2017). However, weather stations near farms may not fully describe the whole picture of the environment inside a barn.

Factors that limit the ability of THI equations to indicate heat stress include not accounting for solar radiation or wind speed or cow-specific factors such as milk yield or stage in lactation and assuming that all cows are affected the same by the same environment (Hammami et al., 2013). Depending on the climate in the region being measured, multiple variations of the THI equation exist to account for differences in humidity or dry-bulb temperature. By comparing 7 different THI equations, Bohmanova et al. (2007) determined that the limiting factor for heat stress in humid climates was humidity and the limiting factor in dry climates was dry-bulb temperature. Mader et al. (2006) stated that wind speed should be included in the THI equation because it can affect temperature. Rather than using mean THI, maximum THI (maximum temperature and minimum $\mathrm{RH}$ ) was found to be a more accurate predictor of heat stress (García-Ispierto et al., 2007; Bernabucci et al., 2014). Researchers have found that high temperatures are often associated with lower RH. Minimum THI is better than maximum THI for describing ambient conditions at night (Vitali et al., 2009). Compared with daily average THI, maximum THI was found to have greater negative effects on milk yield (Ravagnolo et al., 2000).

The amount of solar radiation from both direct and diffuse radiation negatively affects cattle and can increase their sensitivity to heat stress. Direct solar radiation originates from direct sun rays, whereas diffuse radiation comes from the reflection of the blue sky and clouds. Including solar radiation in the THI equation accounts for an environmental variable that could affect the severity of heat stress that occurs (Mader et al., 2006; Herbut and Angrecka, 2018).

Although THI is the most commonly used measurement to indicate heat stress, other indices exist that incorporate other measures. Buffington et al. (1981) formulated an equation that considered dry-bulb temperature, humidity, solar radiation, and wind speed known as black globe humidity index (BGHI). The equation for BGHI is as follows:

$$
\mathrm{BGHI}=\mathrm{t}_{\mathrm{bg}}+0.36 \mathrm{t}_{\mathrm{dp}}+41.5,
$$


where $\mathrm{t}_{\mathrm{bg}}=$ black globe temperature $\left({ }^{\circ} \mathrm{C}\right)$ and $\mathrm{t}_{\mathrm{dp}}=$ dew point temperature $\left({ }^{\circ} \mathrm{C}\right.$; Buffington et al., 1981).

Compared with THI, BGHI had greater correlations with rectal temperature and milk yield in heat stress conditions when cows had an increased exposure to solar radiation. In contrast, under shade conditions where exposure to solar radiation was decreased, no significant differences were found between THI and BGHI. When the use of BGHI was studied by Collier et al. (2005), the researchers reported no significant differences and stated that BGHI could be a better predictor of heat stress than THI.

When wind speed is increased, the convection cooling of cows may be increased, but only if the ambient temperature does not exceed the skin surface temperature of the animal (Davis et al., 2003). By including wind speed in the THI equation, THI values may decrease (Herbut and Angrecka, 2018). A further developed (adjusted) equation for THI has been used for calculating THI that takes into account solar radiation and wind speed:

$$
\begin{aligned}
\text { THIadj }= & 4.51+\text { THI }-(1.922 \times \mathrm{V}) \\
& +(0.0068 \times \mathrm{SR})
\end{aligned}
$$

where $\mathrm{V}=$ air velocity $(\mathrm{m} / \mathrm{s})$ and $\mathrm{SR}=$ intensity of solar radiation $\left(\mathrm{W} / \mathrm{m}^{2}\right.$; Mader et al., 2006).

The THIadj of Mader et al. (2006) may be beneficial when assessing heat stress of cattle in temperate climates. With the inclusion of wind speed and solar radiation, it can better assess cow discomfort in those environments (Hammami et al., 2013). When comparing various THI, large differences have been observed under humid or semiarid climates in the United States (Bohmanova et al., 2007). Future research should focus on finding the best-fit THI for various climates that includes both individual cow variables (e.g., respiration rate, body temperature) and environmental variables to predict cow discomfort.

\section{HOUSING}

Dairy cow housing can negatively affect the severity of heat stress experienced if beneficial modifications are not implemented. As THI increases, heat stress conditions are more likely to occur if barns are designed improperly in regard to building orientation, the building materials used have greater thermal conductivity, natural ventilation is not provided, or barns are overcrowded (Abeni and Bertoni, 2009). Before addressing heat abatement methods, we will discuss types of housing and how they can influence heat stress.
Natural ventilation in freestall barns can help provide relief from the heat. Barns housing dairy cattle typically have a steeply slanted roof with a capped or open ridge vent to enhance natural ventilation (West, 2003). With the high roof, this barn design minimizes the transfer of infrared radiation. The hot air rises to the roof incline and is released through the ridge vent. The ridge vent also increases cross-ventilation from wind movement throughout the barn, further allowing access to fresh air (West, 2003).

\section{HEAT ABATEMENT}

Many researchers have studied heat abatement strategies in the past $40 \mathrm{yr}$, with most studies focusing on cooling cows in confinement-based settings (Tucker et al., 2008; Bucklin et al., 2009; Fournel et al., 2017). Cattle housed on pasture often cannot seek protection from climactic conditions such as heat, rain, wind, or snow (Gregory, 1995). Various management practices are aimed to reduce the negative effects of heat stress on lactating dairy cows, including genetic selection for more heat-tolerant cows, nutritional management, and environmental modification or cow cooling strategies (Beede and Collier, 1986; Dash et al., 2015). Altering the environment is generally an easier and faster way to improve welfare, production, and reproduction performance than improving genetic selection for heattolerant traits (West, 2003; Mader et al., 2006).

Implementing the appropriate cow cooling strategy is an important management decision for dairy producers and can reduce the economic loss associated with heat stress. Cow cooling strategies that are used in confinement settings include fans, shade, natural ventilation, and water-cooling systems (misters, sprinklers; USDA, $2014)$. In $2014,86.2 \%$ of all US dairy operations provided a covered structure or building as shade for cows. In the United States, $25.2 \%$ of all dairy operations have implemented mister or sprinkler systems (USDA, 2016). For cattle on pasture, the provision of natural shade from trees, permanent or portable shade structures, or soaker lines can be mounted onto center pivot irrigation systems to be used as cooling strategies. The utilization and economic impact of cow cooling strategies for pasture-based dairies needs to be studied to better understand the importance of implementing heat abatement for grazing cattle.

\section{Shade}

Shade is beneficial for cattle physiologically, behaviorally, and in terms of production (Muller et al., 1994; Widowski, 2001; Kendall et al., 2006). In summer 
conditions, cows with access to shade have decreased respiration rate $(\mathbf{R R})$ and core body temperatures compared with cattle without shade (Blackshaw and Blackshaw, 1994). When access to shade is provided, cattle will readily use it to alleviate the negative effects of increased heat load (Roman-Ponce et al., 1977; Schütz et al., 2008). If on pasture, cows will search for shade when ambient temperature and solar radiation increase (Kendall et al., 2006). Cattle without access to shade may reduce the time spent grazing when environmental temperatures are high to seek relief from the heat by congregating around the water tank and creating a muddy area to facilitate with cooling. In contrast, cattle with access to shade do not spend time in search of shade at the expense of grazing (Schütz et al., 2008).

Production and physiological changes can be measured to determine when an animal is unable to adapt to a situation. Before production is compromised, the animal will change behavior patterns to alleviate the situation (Schütz et al., 2010). When cattle do not have access to shade, they will find other means to adapt to the environment, such as spending more time standing in response to the increased heat load and spending more time around the water trough (Widowski, 2001; Nordlund et al., 2019). As ambient temperature increases, the percent of cows drinking and grouping around the water supply is greater for unshaded cattle than for shaded cattle (Muller et al., 1994).

Natural shade from trees provides variable protection against solar radiation and wind speed, and it is contingent on height, spacing, and density of various species (Hawke and Wedderburn, 1994). When trees are intentionally planted and managed to provide adequate shade and protection, this method of heat abatement can be useful in minimizing the negative effects of heat stress (Gregory, 1995). However, trees can only provide shade for a portion of the day, depending on where they are located relative to the sun. Cows may crowd around a shade tree because there is not enough shade space, which often leads to soil erosion, may expose the roots, and can damage or even kill the tree. When animals crowd together in one area, manure and urine will accumulate, creating a potential health issue and reducing pasture fertility in the long run (Peterson and Gerrish, 1995). When walking, natural leg movements can carry contaminants around the surface of the udder. Cows that are standing, lying, and walking in deep mud and manure have the potential to contract mastitis and hoof diseases (Jones and Swisher, 2009). For example, the cows in Figure 1 were in a control group for an unpublished heat stress study in Mississippi. These cows had no access to heat abatement and seemingly attempted to cool off by crowding in one area and lying in the resulting mud.
Schütz et al. (2010) studied how the amount of shade provided influences the behavior and physiology of Holstein cattle on pasture. Three treatments were applied: no shade, $2.4 \mathrm{~m}^{2}$ shade/cow, or $9.6 \mathrm{~m}^{2}$ shade/cow. The researchers reported that cows with access to the most shade spent twice as much time in shade compared with the cows with the lesser amount of shade (24 vs. $50 \%$ of observations for $2.4 \mathrm{~m}^{2}$ and $9.6 \mathrm{~m}^{2}$, respectively) and engaged in fewer aggressive interactions (10.7 vs. 3.2 for $2.4 \mathrm{~m}^{2}$ and $9.6 \mathrm{~m}^{2}$ shade/cow, respectively). When the size of the shaded area is adequate, cows will spend more time in the shade instead of competing for it. Cows with access to the $9.6-\mathrm{m}^{2}$ shade space spent more time lying in the shade than cows provided with $2.4 \mathrm{~m}^{2}$ (36\% and 10\%, respectively). Cows with access to the larger shade had lower RR than cows with the smaller shade $\left(62,57\right.$, and 51 breaths/min for no shade, $2.4 \mathrm{~m}^{2}$, and $9.6 \mathrm{~m}^{2}$ ). Roman-Ponce et al. (1977) reported that cows that were provided shade had decreased RR (54 and 82 breaths/min, respectively) and lower rectal temperatures ( 38.9 and $39.4^{\circ} \mathrm{C}$, respectively), and produced $10 \%$ more milk than cows without access to shade.

Increased water consumption in periods of heat stress may also be a method for reducing heat load. Palacio et al. (2015) found that, in an 8-wk study, grazing cows with access to shade were observed at the water trough

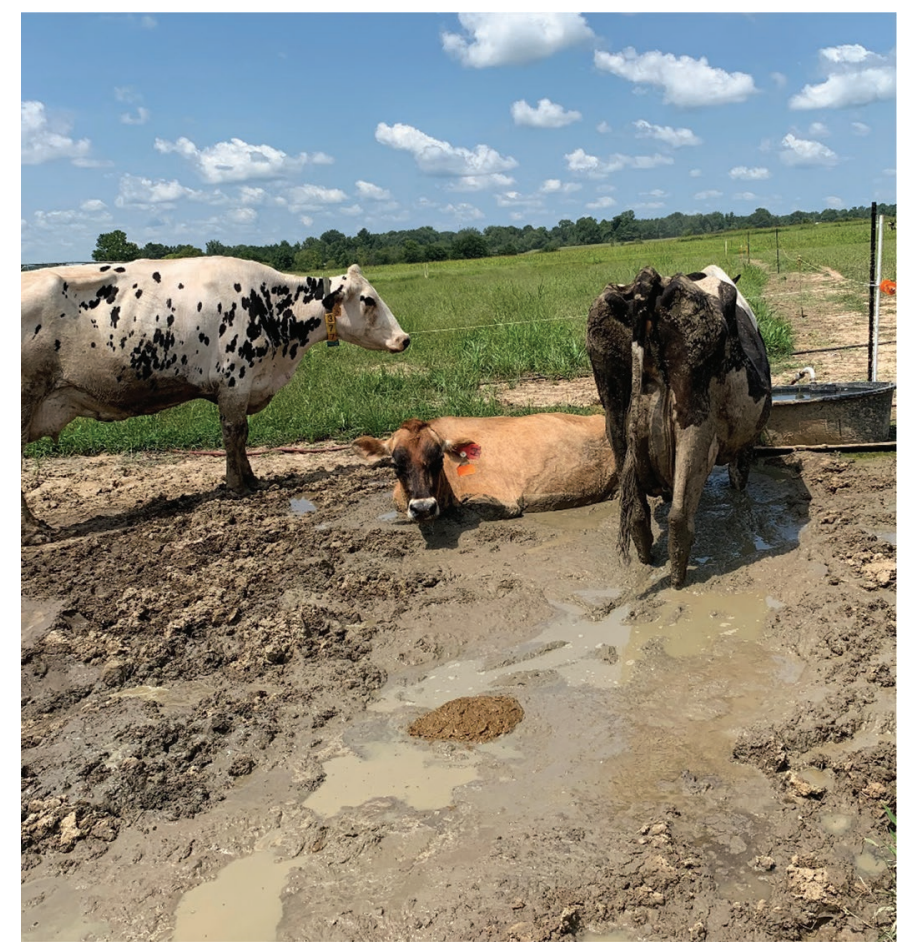

Figure 1. Cows in a control group (no heat abatement provided) on a heat stress study in Mississippi standing and lying in deep mud and manure (photograph courtesy of C. Becker). 
on average $34.2 \%$ less than cows without shade access. Previous studies support these results in that lactating cows increased their water intake and increased time spent around the water trough when there was minimal or no access to shade with increasing heat loads (Schütz et al., 2010). Evaporating water from the water trough may create a more ideal microclimate and attract the cows (Palacio et al., 2015). When cows are congregating around a water source, this can lead to overgrazing of the area around the trough and undergrazing of other areas.

The provision of shade is one of the easiest heat abatement methods to implement. Shade protects against solar radiation but may not affect air temperature or humidity around cows, which may inhibit their natural ability to dissipate heat (Flamenbaum et al., 1986; Renaudeau et al., 2012). Therefore, supplementing shade with additional cooling strategies, such as fans or sprinklers, could enhance cooling capabilities and further relieve the negative effects of heat stress.

\section{Evaporative Cooling}

Providing sprinklers or misters could be an effective method to decrease the accumulated heat load and enhance cows' natural heat dissipation (Schütz et al., 2011). Using water for cooling, with or without another cooling strategy, such as fans, can be more effective at reducing heat load than shade alone (Mitlöhner et al., 2001; Correa-Calderon et al., 2004). Compared with shade, fans, or sprinklers alone, a combination of fans and sprinklers were more effective at decreasing body temperature and RR due to the increase in evaporative cooling (Correa-Calderon et al., 2004).

In an Arizona study, Correa-Calderon et al. (2004) evaluated the effectiveness of 2 different cooling strategies on physiological responses in the summer. The study included Holstein and Brown Swiss cows, with a control group (no cooling) and 2 treatment groups; treatment group 1 had access to misters and fan cooling and treatment group 2 had access to sprinklers with fan cooling. The researchers reported that the cows that had access to both cooling systems had reduced rectal temperatures (by $0.7^{\circ} \mathrm{C}$ for group 1 and by $0.9^{\circ} \mathrm{C}$ for group 2) compared with the control group. Respiration rates of the control group were 20.5 breaths/min higher than that of the mist and fan group, and 32 breaths/ min higher than that of the evaporatively cooled group (Correa-Calderon et al., 2004). In the same study, Brown Swiss cows had lower overall rectal temperatures than Holstein cows, regardless of treatment. This response could be attributable to Brown Swiss cows having greater tolerance to heat stress due to their lower milk production and therefore lower metabolic heat production compared with Holstein cows. These results are in agreement with results from other studies indicating that Brown Swiss cows are more heat tolerant than Holstein cows (Johnson, 1965; Armstrong and Hillman, 1998).

Schütz et al. (2011) found that, when given the option, cows on pasture will choose shade over sprinklers. In their study, $62 \%$ of study cows chose shade over sprinklers and $65 \%$ chose shade over no form of heat abatement. Respiration rate, skin surface temperature, and rectal temperature were recorded before and 10 min after treatment with sprinklers, shade, or no heat abatement. Even though shade was preferred by cows, sprinklers were significantly better than shade at reducing RR and decreasing skin surface temperature. Cows that went to the sprinklers had a greater decrease in core body temperature as heat load index, a weather measurement that includes ambient temperature, humidity, black globe temperature, and wind speed, increased $\left(0.008,0.001\right.$, and $0.0001^{\circ} \mathrm{C}$ decrease in body temperature per unit increase of heat load index for sprinklers, shade, and ambient conditions, respectively).

Kendall et al. (2007) reported that cows cooled with sprinklers spend more time with their heads in a low position, which could mean the cows were attempting to reduce the exposure of water to the head. Overhead misters or sprinklers may be aversive for cows. When exposed to wind and rain, cattle are 5 times more likely to hold their head in a lower position compared with cows with shelter. This may be an attempt to protect sensitive areas, such as the ears, from being exposed (Tucker et al., 2008). Greater water flow rates from sprinklers can cause cows to lower their head more often due to the greater water impact. Chen et al. (2016a) found that cows lowered their head 5 times more often with $4.5 \mathrm{~L} / \mathrm{min}$ of water compared with $0.4 \mathrm{~L} / \mathrm{min}$ of water. The behavior exhibited by the cows may indicate that the cows are attempting to avoid the greater water flow rate, but the researchers mentioned that the cows did not avoid the greater flow rate altogether and no difference in preference was observed.

Kendall et al. (2007) studied the effects of shade and sprinklers, either alone or in combination, on the physiological and behavioral responses of grazing dairy cows. The researchers were specifically studying the effectiveness of different cooling strategies applied for $90 \mathrm{~min}$ before the afternoon milking. Each treatment was applied in a holding pen. There were 4 treatment groups: shade, sprinklers, shade and sprinklers, and control with no heat abatement. Sprinklers and shade reduced RR by 60 and $30 \%$ compared with control cows. The combination of shade and sprinklers was most effective in reducing $\mathrm{RR}$. These results are similar to those of another study that used sprinklers for cooling (Tarazón- 
Herrera et al., 1999). Additionally, Kendall et al. (2007) explained that the cows on the shade treatment had a lower body temperature (by $0.3^{\circ} \mathrm{C}$ ) than control cows. In contrast, cows under sprinklers had a delay in body temperature reduction but a greater overall reduction after the 90-min treatment compared with the control group.

Another study evaluated how and when dairy cows voluntarily used an overhead water source that was kept separate from sources such as feed, and how the use of this voluntary shower affected physiological and behavioral indices of heat stress (Legrand et al., 2011). This study revealed a substantial amount of variability in shower use between animals, ranging from 0.0 to $8.2 \mathrm{~h} / 24 \mathrm{~h}$. As ambient temperature increased by $1^{\circ} \mathrm{C}$, shower use increased by $0.3 \mathrm{~h}$. Cows showed a preference for shower use between the hours of 1000 and $1900 \mathrm{~h}$, spending $89 \pm 12 \%$ of time in the shower. Respiration rates did not differ between cows offered a voluntary shower and the control group. However, body temperature decreased by $0.2^{\circ} \mathrm{C}$ in the shower treatment group compared with the control. The researchers concluded that when given the option, cows will use a voluntary shower to reduce the accumulated heat load. However, the between-cow variability in use of the shower may indicate that the behavioral response to water needs to be considered when designing a sprinkler system for cooling cows (Legrand et al., 2011).

Water droplet size is an important aspect to consider when assessing cow cooling. To adequately cool cows with water, droplets must thoroughly wet the hides of the animals. However, if water accumulates on the hide, humidity around the animal can increase and may reduce the effectiveness of the cooling strategy (Means et al., 1992). In regions with high relative humidity, misters may add to the humidity of the environment, preventing the cow from effectively dissipating heat via evaporation. However, in an Alabama study where relative humidity was high, researchers observed no differences in respiration rates between treatments that had access to fans and sprinklers compared with fans and misters (Lin et al., 1998). Chen et al. (2013) tested how sprinkler flow rate and size of the water droplets affected physiological responses (e.g., RR, body temperature, skin temperature) of cows in a hot, dry climate. The researchers observed that droplet size did not affect cooling but flow rate did affect several physiological measures. Respiration rate and skin temperature were reduced compared with baseline, and body temperature remained below baseline for $30 \mathrm{~min}$ after treatment was applied. The researchers concluded that the most efficient sprinkler flow rate that best balanced cow cooling and water usage was $1.3 \mathrm{~L} / \mathrm{min}$. It was not evident that cow cooling was improved by a flow rate greater than $1.3 \mathrm{~L} / \mathrm{min}$ (Chen et al., 2013).

When cooling cows with misters or sprinklers, water usage can become a sustainability concern (von Keyserlingk et al., 2013). Decreasing rainfall, changes in precipitation patterns, and rising temperatures may decrease the availability of potable water to use for cooling cattle (Rosenstock et al., 2006). Sprinklers in dairy cattle barns are typically mounted above the feed bunk and activated intermittently for the whole pen when the air temperature reaches a specific threshold set by the producer. The sprinklers are activated regardless of whether cows are standing under them at the feed bunk, which can lead to wasted water. Chen et al. (2016b) reported that at flow rates of 1.3 and 4.9 $\mathrm{L} / \mathrm{min}$, cows modified their behavior to maintain time spent at the feed bunk while avoiding walking through water and getting their heads sprayed. Visits to the feed bunk were longer and less frequent when cows were provided with sprinklers compared with without sprinklers. With both flow rates, cows had reduced body temperatures, greater milk yields, and similar behavioral responses, but the $1.3 \mathrm{~L} / \mathrm{min}$ flow rate used $73 \%$ less water than the $4.9 \mathrm{~L} / \mathrm{min}$ rate.

To effectively and efficiently cool cattle, the amount of time sprinklers are on is important. Combining the use of repeated wetting with sprinklers and fans has proven to be the most efficient approach to cooling cows compared with using only fans in regions with humid climates (Berman, 2005). Flamenbaum et al. (1986) found that wetting cows for 20 to $30 \mathrm{~s}$ was more effective than wetting cows for only $10 \mathrm{~s}$. In the same study, when cows were cooled with sprinklers 5 times/ day for 30 min each cooling period, body temperatures remained below $39^{\circ} \mathrm{C}$, within the normal body temperature range, for $24 \mathrm{~h}$. A common sprinkler timing schedule may include a 5 -min-long cycle, with $30 \mathrm{~s}$ of wetting and $2.5 \mathrm{~min}$ of forced ventilation (fans). Flamenbaum et al. (1986) reported that 5 to 7 cooling sessions (sprinklers and fans) each day for 30 to $45 \mathrm{~min}$ each positively influenced milk yield during periods of heat stress. In another study, applying 8 cooling sessions per day improved reproductive parameters (shorter estrous cycle, shorter follicle dominance period, and decreased chance of an older follicle ovulating) compared with only 5 cooling sessions (Honig et al., 2016).

Tresoldi et al. (2018) conducted a study to evaluate the cooling effectiveness of 4 different water spraying strategies, using 2 water volumes ( 74 or $44 \mathrm{~L} /$ nozzle) over a 45 -min period. The water spraying strategies used were $1.5 \mathrm{~min}$ on $/ 3 \mathrm{~min}$ off, 10 cycles; $1.5 \mathrm{~min}$ on $/ 6$ min off, 6 cycles; 3 min on $/ 6$ min off, 5 cycles; and 3 min on/12 min off, 3 cycles; with a control treatment 
Table 1. List of heat stress studies discussed in this review using different heat abatement strategies and the variables that the researchers measured

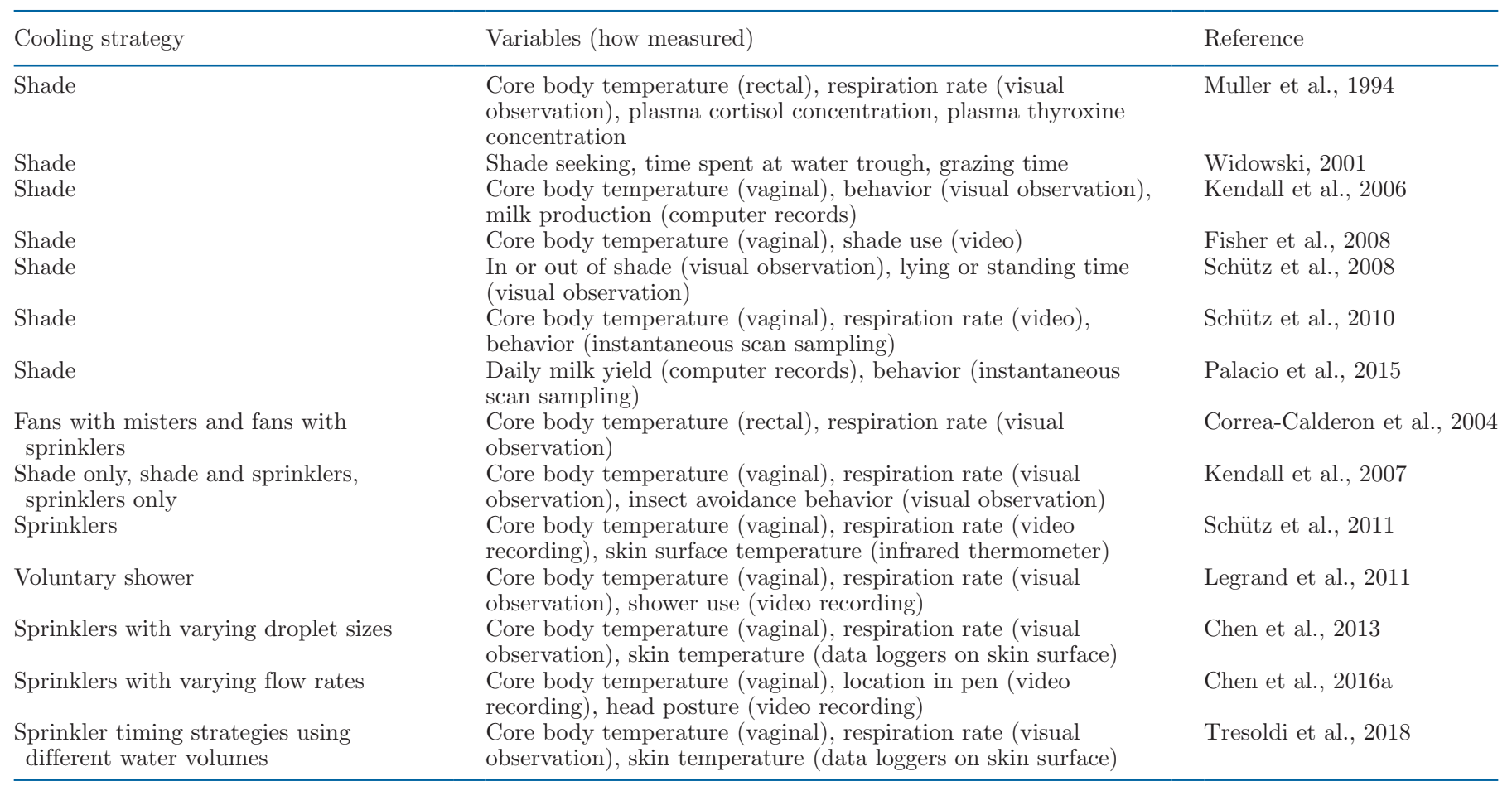

group that had access to shade only. The researchers measured body temperature, RR, skin temperature of the leg and shoulder, and air temperature surrounding the cow. Compared with the control group, all sprinkler treatments reduced heat load. Applying water to the cows more frequently reduced RR by 7 breaths/min. When the time the sprinklers were on increased from 1.5 to 3 min, body temperature was reduced by at least $0.1^{\circ} \mathrm{C}$ and leg temperature by $\geq 0.2^{\circ} \mathrm{C}$ after the 45 -min period. Increasing the time that sprinklers were kept on or decreasing the time sprinklers were turned off improved cow cooling in this study (Tresoldi et al., 2018).

In a grazing system during summer, body temperatures of cows reach a maximum during and after the p.m. milking (Kendall et al., 2007). Cooling cows in the holding pen can help alleviate the accumulated heat load from walking to the milking parlor. When cattle are cooled with fans and sprinklers for 20 to 30 min in the holding pen after walking to the milking parlor, body temperature and RR may be reduced for a short period (Valtorta and Gallardo, 2004). Araki et al. (1985) reported that when cows were cooled with fans and sprinklers in the holding pen before milking, body temperature was reduced for 2 to $4 \mathrm{~h}$ after milking compared with cows that received no cooling in the holding pen. In hot weather, shade and sprinklers can be used in the holding pen to reduce the effects of heat stress on dairy cows. Table 1 summarizes the studies discussed in this review.

\section{CONCLUSIONS}

Heat stress is an important issue in the southeastern US and contributes to a huge economic loss annually to the dairy industry. When THI is monitored, producers can assess the level of heat stress that their cows may be under and provide an appropriate heat abatement strategy. Provision of shade, fans, misters, or any combination of the aforementioned techniques can help alleviate some of the negative effects associated with heat stress.

\section{ACKNOWLEDGMENTS}

The authors have stated no conflicts of interest.

\section{REFERENCES}

Abeni, F., and G. Bertoni. 2009. Main causes of poor animal welfare in intensively reared dairy cows. Ital. J. Anim. Sci. 8(Suppl. 1):45-66. https://doi.org/10.4081/ijas.2009.s1.45.

Araki, C. T., R. M. Nakamura, L. W. G. Kam, and N. L. Clarke. 1985. Diurnal temperature patterns of early lactating cows with milking parlor cooling. J. Dairy Sci. 68:1496-1501. https://doi.org/10 $.3168 /$ jds.S0022-0302(85)80988-7. 
Armstrong, D. V., and P. E. Hillman. 1998. Evaluation of Brown Swiss, Holstein and Jerseys under hot arid climates for dairy production. Pages 153-165 in Proc. Southwest Nutrition and Management Conference, Tucson, AZ. University of Arizona, Tucson.

Beede, D. K., and R. J. Collier. 1986. Potential nutritional strategies for intensively managed cattle during thermal stress. J. Dairy Sci. 62:543-554. https://doi.org/10.2527/jas1986.622543x.

Berman, A. 2005. Estimates of heat stress relief needs for Holstein dairy cows. J. Anim. Sci. 83:1377-1384. https://doi.org/10.2527/ 2005.8361377x.

Bernabucci, U., S. Biffani, L. Buggiotti, A. Vitali, N. Lacetera, and A. Nardone. 2014. The effects of heat stress in Italian Holstein dairy cattle. J. Dairy Sci. 97:471-486. https://doi.org/10.3168/jds.2013 $-6611$.

Bianca, W. 1962. Relative importance of dry- and wet-bulb temperatures in causing heat stress in cattle. Nature 195:251-252. https:/ /doi.org/10.1038/195251a0.

Blackshaw, J. K., and A. W. Blackshaw. 1994. Heat stress in cattle and the effect of shade on production and behaviour: A review. Aust. J. Exp. Agric. 34:285-295. https://doi.org/10.1071/EA9940285.

Bohmanova, J., I. Misztal, and J. B. Cole. 2007. Temperature-humidity indices as indicators of milk production losses due to heat stress. J. Dairy Sci. 90:1947-1956. https://doi.org/10.3168/jds.2006-513.

Brown-Brandl, T. M., R. E. Eigenberg, J. A. Nienaber, and G. L. Hahn. 2005. Dynamic response indicators of heat stress in shaded and non-shaded feedlot cattle: Part 1. Analyses of indicators. Biosyst. Eng. 90:451-462. https://doi.org/10.1016/j.biosystemseng 2004.12.006.

Bucklin, R. A., D. R. Bray, J. G. Martin, L. Carlos, and V. Carvalho. 2009. Environmental temperatures in Florida dairy housing. Appl. Eng. Agric. 25:727-735. https://doi.org/10.13031/2013.28851.

Buffington, D. E., A. Collazo-Arocho, G. H. Canton, D. Pitt, W. W. Thatcher, and R. J. Collier. 1981. Black globe-humidity index (BGHI) as comfort equation for dairy cows. Trans. ASAE 24:711714. https://doi.org/10.13031/2013.34325.

Chen, J. M., K. E. Schütz, and C. B. Tucker. 2013. Dairy cows use and prefer feed bunks fitted with sprinklers. J. Dairy Sci. 96:50355045. https://doi.org/10.3168/jds.2012-6282.

Chen, J. M., K. E. Schütz, and C. B. Tucker. 2016a. Sprinkler flow rate affects dairy cattle avoidance of spray to the head, but not overall, in an aversion race. Appl. Anim. Behav. Sci. 179:23-31. https:// doi.org/10.1016/j.applanim.2016.03.007.

Chen, J. M., K. E. Schütz, and C. B. Tucker. 2016b. Cooling cows efficiently with water spray: Behavioral, physiological, and production responses to sprinklers at the feed bunk. J. Dairy Sci. 99:4607-4618. https://doi.org/10.3168/jds.2015-10714.

Collier, R. J., R. B. Zimbelman, R. P. Rhoads, M. L. Rhoads, and L. H. Baumgard. 2005. A re-evaluation of the impact of temperature humidity index (THI) and black globe humidity index (BGHI) on milk production in high producing dairy cows. Pages $113-125$ in Proc. Western Dairy Management Conference, Reno, NV. University of Arizona, Tucson, AZ.

Correa-Calderon, A., D. Armstrong, D. Ray, S. DeNise, M. Enns, and C. Howison. 2004. Thermoregulatory responses of Holstein and Brown Swiss heat-stressed dairy cows to two different cooling systems. Int. J. Biometeorol. 48:142-148. https://doi.org/10.1007/ s00484-003-0194-y.

Dash, S., A. Chakravarty, V. Sah, V. Jamuna, R. Behera, N. Kashyap, and B. Deshmukh. 2015. Influence of temperature and humidity on pregnancy rate of Murrah buffaloes under subtropical climate. Asian Australas. J. Anim. Sci. 28:943-950. https://doi.org/10 .5713 /ajas.14.0825.

Davis, M. S., T. L. Mader, S. M. Holt, and A. M. Parkhurst. 2003. Strategies to reduce feedlot cattle heat stress: Effects on tympanic temperature. J. Anim. Sci. 81:649-661. https://doi.org/10.2527/ 2003.813649x.

De Rensis, F., I. Garcia-Ispierto, and F. López-Gatius. 2015. Seasonal heat stress: Clinical implications and hormone treatments for the fertility of dairy cows. Theriogenology 84:659-666. https://doi .org/10.1016/j.theriogenology.2015.04.021.
Fisher, A. D., N. Roberts, S. J. Bluett, G. A. Verkerk, and L. R. Matthews. 2008. Effects of shade provision on the behaviour, body temperature and milk production of grazing dairy cows during a New Zealand summer. N. Z. J. Agric. Res. 51:99-105.

Flamenbaum, I., D. Wolfenson, M. Mamen, and A. Berman. 1986. Cooling dairy cattle by a combination of sprinkling and forced ventilation and its implementation in the shelter system. J. Dairy Sci. 69:3140-3147. https://doi.org/10.3168/jds.S0022-0302(86)80778 $-0$.

Fournel, S., V. Ouellet, and E. Charbonneau. 2017. Practices for alleviating heat stress of dairy cows in humid continental climates: A literature review. Animals (Basel) 7:37.

García-Ispierto, I., F. López-Gatius, G. Bech-Sabat, P. Santolaria, J. Yániz, C. Nogareda, F. De Rensis, and M. López-Béjar. 2007. Climate factors affecting conception rate of high producing dairy cows in northeastern Spain. Theriogenology 67:1379-1385. https:/ /doi.org/10.1016/j.theriogenology.2007.02.009.

Gaughan, J. B., T. L. Mader, S. M. Holt, and A. Lisle. 2008. A new heat load index for feedlot cattle. J. Anim. Sci. 86:226-234. https: //doi.org/10.2527/jas.2007-0305.

Gregory, N. G. 1995. The role of shelterbelts in protecting livestock: A review. N. Z. J. Agric. Res. 38:423-450. https://doi.org/10.1080/ 00288233.1995 .9513146$.

Hammami, H., J. Bormann, N. M'hamdi, H. H. Montaldo, and N. Gengler. 2013. Evaluation of heat stress effects on production traits and somatic cell score of Holsteins in a temperate environment. J. Dairy Sci. 96:1844-1855. https://doi.org/10.3168/jds.2012-5947.

Hawke, M. F., and M. E. Wedderburn. 1994. Microclimate changes under Pinus Radiata agroforestry regimes in New Zealand. Agric. For. Meteorol. 71:133-145. https://doi.org/10.1016/0168 -1923(94)90104-X.

Herbut, P., and S. Angrecka. 2018. Relationship between THI level and dairy cows' behaviour during summer period. Ital. J. Anim. Sci. 17:226-233. https://doi.org/10.1080/1828051X.2017.1333892.

Honig, H., L. Ofer, M. Kaim, S. Jacobi, D. Shinder, and E. Gershon. 2016. The effect of cooling management on blood flow to the dominant follicle and estrous cycle length at heat stress. Theriogenology 86:626-634. https://doi.org/10.1016/j.theriogenology.2016.02.017.

IPCC (Intergovernmental Panel on Climate Change). 2018. Climate Change: Special report; Summary for policymakers. https://www .ipcc.ch/site/assets/uploads/sites/2/2019/05/SR15_SPM_version _report_LR.pdf.

Johnson, H. D. 1965. Environmental temperature and lactation (with special reference to cattle). Int. J. Biometeorol. 9:103-116. https:/ /doi.org/10.1007/BF02188466.

Jones, G. M., and J. M. Swisher Jr. 2009. Environmental streptococcal and coliform mastitis. Virginia Cooperative Extension Publication 404-234. Virginia Tech, Blacksburg, VA.

Kendall, P. E., P. P. Nielsen, J. R. Webster, G. A. Verkerk, R. P. Littlejohn, and L. R. Matthews. 2006. The effects of providing shade to lactating dairy cows in a temperate climate. Livest. Sci. 103:148-157. https://doi.org/10.1016/j.livsci.2006.02.004.

Kendall, P. E., G. Verkerk, J. Webster, and C. Tucker. 2007. Sprinklers and shade cool cows and reduce insect-avoidance behavior in pasture-based dairy systems. J. Dairy Sci. 90:3671-3680. https:// doi.org/10.3168/jds.2006-766.

Legrand, A., K. E. Schütz, and C. B. Tucker. 2011. Using water to cool cattle: Behavioral and physiological changes associated with voluntary use of cow showers. J. Dairy Sci. 94:3376-3386. https:// doi.org/10.3168/jds.2010-3901.

Lin, J. C., B. R. Moss, J. L. Koon, C. A. Flood, R. C. Smith III, K. A. Cummins, and D. A. Coleman. 1998. Comparison of various fan, sprinkler, and mister systems in reducing heat stress in dairy cows. Appl. Eng. Agric. 14:177-182.

Mader, T. L., M. S. Davis, and T. Brown-Brandl. 2006. Environmental factors influencing heat stress in feedlot cattle. J. Anim. Sci. 84:712-719. https://doi.org/10.2527/2006.843712x.

Means, S. L., R. A. Bucklin, R. A. Nordstedt, D. K. Beede, D. R. Bray, C. J. Wilcox, and W. K. Sanchez. 1992. Water application rates for a sprinkler and fan dairy cooling system in hot humid 
climates. Appl. Eng. Agric. 8:375-379. https://doi.org/10.13031/ 2013.26080 .

Mitlöhner, F. M., J. L. Morrow, J. W. Dailey, S. C. Wilson, M. L. Galyean, M. F. Miller, and J. J. McGlone. 2001. Shade and water misting effects on behavior, physiology, performance, and carcass traits of heat-stressed feedlot cattle. J. Anim. Sci. 79:2327-2335.

Muller, C. J. C., J. A. Botha, W. A. Coetzer, and W. A. Smith. 1994. Effect of shade on various parameters of Friesian cows in a Mediterranean climate in South Africa. 2. Physiological responses. S. Afr. J. Anim. Sci. 24:56-60.

Nienaber, J. A., G. Hahn, and R. Eigenberg. 1999. Quantifying livestock responses for heat stress management: A review. Int. J. Biometeorol. 42:183-188. https://doi.org/10.1007/s004840050103.

Nordlund, K. V., P. Strassburg, T. B. Bennett, G. R. Oetzel, and N. B. Cook. 2019. Thermodynamics of standing and lying behavior in lactating dairy cows in freestall and parlor holding pens during conditions of heat stress. J. Dairy Sci. 102:6495-6507. https://doi .org/10.3168/jds.2018-15891.

Palacio, S., R. Bergeron, S. Lachance, and E. Vasseur. 2015. The effects of providing portable shade at pasture on dairy cow behavior and physiology. J. Dairy Sci. 98:6085-6093. https://doi.org/10 $.3168 / j d s .2014-8932$.

Peterson, P. R., and J. R. Gerrish. 1995. Grazing management affects manure distribution by beef cattle. Animal Forage and Grassland Council. 4:170-174.

Polsky, L., and M. A. von Keyserlingk. 2017. Invited review: Effects of heat stress on dairy cattle welfare. J. Dairy Sci. 100:8645-8657. https://doi.org/10.3168/jds.2017-12651.

Ravagnolo, O., I. Misztal, and G. Hoogenboom. 2000. Genetic component of heat stress in dairy cattle, development of heat index function. J. Dairy Sci. 83:2120-2125. https://doi.org/10.3168/jds .S0022-0302(00)75094-6.

Renaudeau, D., A. Collin, S. Yahav, V. de Basilio, J. L. Gourdine, and R. J. Collier. 2012. Adaptation to hot climate strategies to alleviate heat stress in livestock production. Animal 6:707-728.

Roman-Ponce, H., W. W. Thatcher, D. E. Buffington, C. J. Wilcox, and H. H. Van Horn. 1977. Physiological and production responses of dairy cattle to a shade structure in a subtropical environment. J. Dairy Sci. 60:424-430. https://doi.org/10.3168/jds.S0022 -0302(77)83882-4.

Rosenstock, T., S. Smukler, and T. Cavagnaro. 2006. California agricultural landscapes and climate change. Pages 3-12 in Climate Change: Challenges and solutions for California agricultural landscapes. T. Cavagnaro, L. Jackson, and K. Scow, ed. California Climate Change Center, Sacramento, CA.

Schütz, K. E., N. R. Cox, and L. R. Matthews. 2008. How important is shade to dairy cattle? Choice between shade or lying following different levels of lying deprivation. Appl. Anim. Behav. Sci. 114:307-318. https://doi.org/10.1016/j.applanim.2008.04.001.

Schütz, K. E., A. Rogers, N. Cox, J. Webster, and C. Tucker. 2011. Dairy cattle prefer shade over sprinklers: Effects on behavior and physiology. J. Dairy Sci. 94:273-283. https://doi.org/10.3168/jds .2010-3608.

Schütz, K. E., A. R. Rogers, Y. A. Poulouin, N. R. Cox, and C. B. Tucker. 2010. The amount of shade influences the behavior and physiology of dairy cattle. J. Dairy Sci. 93:125-133. https://doi .org/10.3168/jds.2009-2416.

Spiers, D. E., J. N. Spain, J. D. Sampson, and R. P. Rhoads. 2004. Use of physiological parameters to predict milk yield and feed intake in heat-stressed dairy cows. J. Therm. Biol. 29:759-764. https://doi .org/10.1016/j.jtherbio.2004.08.051.

St-Pierre, N. R., B. Cobanov, and G. Schnitkey. 2003. Economic losses from heat stress by US livestock industries. J. Dairy Sci. 86(E Suppl.):E52-E77.

Tao, S., R. Orellana, X. Weng, T. Marins, G. Dahl, and J. Bernard. 2018. Symposium review: The influences of heat stress on bovine mammary gland function. J. Dairy Sci. 101:5642-5654. https://doi .org/10.3168/jds.2017-13727.

Tarazón-Herrera, M., J. Huber, J. Santos, H. Mena, L. Nusso, and C. Nussio. 1999. Effects of bovine somatotropin and evaporative cooling plus shade on lactation performance of cows during summer heat stress. J. Dairy Sci. 82:2352-2357. https://doi.org/10.3168/ jds.S0022-0302(99)75485-8.

Thom, E. C. 1959. The discomfort index. Weatherwise 12:57-61. https: //doi.org/10.1080/00431672.1959.9926960.

Tresoldi, G., K. E. Schütz, and C. B. Tucker. 2018. Cooling cows with sprinklers: Spray duration affects the physiological responses to heat load. J. Dairy Sci. 101:4412-4423.

Tucker, C. B., A. R. Rogers, and K. E. Schütz. 2008. Effect of solar radiation on dairy cattle behaviour, use of shade and body temperature in a pasture-based system. Appl. Anim. Behav. Sci. 109:141-154. https://doi.org/10.1016/j.applanim.2007.03.015.

USDA. 2014. Milk production, disposition, and income 2013 summary. http://usda.mannlib.cornell.edu/usda/ current/MilkProdDi/ MilkProdDi-04-29-2014.txt.

USDA. 2016. Dairy cattle management practices in the United States, 2014. USDA Animal and Plant Health Inspection Service-Veterinary Services, Center for Epidemiology and Animal Health, Fort Collins, CO.

Valtorta, S. E., and M. R. Gallardo. 2004. Evaporative cooling for Holstein dairy cows under grazing conditions. Int. J. Biometeorol. 48:213-217. https://doi.org/10.1007/s00484-003-0196-9.

Vitali, A., M. Segnalini, L. Bertocchi, U. Bernabucci, A. Nardone, and N. Lacetera. 2009. Seasonal pattern of mortality and relationships between mortality and temperature-humidity index in dairy cows. J. Dairy Sci. 92:3781-3790. https://doi.org/10.3168/jds.2009 $-2127$.

von Keyserlingk, M. A. G., N. P. Martin, E. Kebreab, K. F. Knowlton, R. J. Grant, M. Stephenson II, C. J. Sniffen, J. P. Harner III, A. D. Wright, and S. I. Smith. 2013. Invited review: Sustainability of the US dairy industry. J. Dairy Sci. 96:5405-5425.

West, J. W. 2003. Effects of heat-stress on production in dairy cattle. J. Dairy Sci. 86:2131-2144. https://doi.org/10.3168/jds.S0022 -0302(03)73803-X.

Widowski, T. M. 2001. Shade-seeking behavior of rotationally-grazed cows and calves in a moderate climate. Pages 632-639 in Livestock Environment IV: Proceedings of the 6th International Symposium Louisville, KY. American Society of Agricultural and Biological Engineers, St. Joseph, MI.

\section{ORCIDS}

C. A. Becker @ https://orcid.org/0000-0002-4713-4298

A. E. Stone $\odot$ https://orcid.org/0000-0001-5687-3394 